\title{
Effect of nedocromil sodium on the airway response to inhaled capsaicin in normal subjects
}

\author{
L HANSSON, NOZHAT B CHOUDRY, R W FULLER, N B PRIDE
}

From the Departments of Clinical Pharmacology and Medicine, Royal Postgraduate Medical School, London, and the Department of Medicine, University Hospital, Lund, Sweden

ABSTRACT In six normal subjects treatment with $4 \mathrm{mg}$ nedocromil sodium failed to alter the cough and bronchoconstriction induced by inhaled capsaicin. Because nedocromil has previously been shown to inhibit reflex bronchoconstriction provoked by inhaled sulphur dioxide and inhaled bradykinin, the results suggest that inhaled capsaicin acts on different nerve fibres.

Nedocromil sodium is a potent inhibitor of mucosal and connective tissue mast cells in primates and it inhibits antigen induced bronchoconstriction in man.' It is also a potent inhibitor of reflex bronchoconstriction induced by inhaled sulphur dioxide ${ }^{2}$ and bradykinin, ${ }^{3}$ both of which may act by stimulating airway $\mathbf{C}$ fibres. Capsaicin, the active ingredient of red pepper, in animals has been shown to stimulate $C$ fibres accessible to both pulmonary and bronchial artery circulation. Inhaled capsaicin in man causes reproducible cough ${ }^{4}$ and bronchoconstriction. ${ }^{5}$ These effects are inhibited by lignocaine $e^{4}$ and muscarinic antagonists, ${ }^{5}$ suggesting that they are due to stimulation of a reflex mechanism. We have therefore examined whether inhaled nedocromil sodium (4 $\mathrm{mg}$ ) alters the cough and reflex bronchoconstriction induced by inhaling capsaicin.

\section{Methods}

Six healthy subjects (three female) aged 23-34 years took part in the study, which had the permission of the local medical school ethics committee. For the construction of capsaicin cough dose-response (CDR) curves the subjects took single breaths at one minute intervals of either $0.9 \% \mathrm{w} / \mathrm{v}$ sodium chloride or a range of doses of capsaicin $(0.4-50 \mathrm{nmol})$ dissolved in $0.9 \% \mathrm{NaCl}$ with $1 \% \mathrm{w} / \mathrm{v}$ ethanol in random order from a nebuliser controlled by a breath activated dosimeter (P K Morgan) with an output $0.02 \mathrm{ml}$ per breath. The number of coughs was recorded by a microphone connected to a pen recorder running at $50 \mathrm{~mm} / \mathrm{s}$ (Mingograph). Total respiratory resistance $\left(R_{r s}\right)$ was measured by a forced oscillation technique that averaged resistance over 16 second periods of tidal breathing. ${ }^{6}$ Three

Address for reprint requests: Dr R W Fuller, Department of Clinical Pharmacology, Royal Postgraduate Medical School, London W12 0HS.

Accepted 14 July 1988 baseline measurements of $R_{r s}$ were performed with the subjects supporting the floor of the mouth and cheeks while breathing quietly on to a mouthpiece attached to the oscillation apparatus. The $R_{r s}$ at $6 \mathrm{~Hz}$ was then recorded. Subjects then inhaled a single breath of the highest dose of capsaicin that caused less than two coughs during the preliminary CDR manoeuvre and $R_{r s}$ at $6 \mathrm{~Hz}$ was recorded over the following 16 seconds. The percentage increase in $R_{r s}$ was then calculated from the mean of the previous baseline measurements. Subjects attended the laboratory on two occasions and had capsaicin CDR and $R_{\mathrm{rs}}$ responses recorded before inhaling two puffs of either nedocromil sodium ( $2 \mathrm{mg} / \mathrm{puff}$ ) or matched placebo in a randomised double blind fashion. Fifteen minutes later the capsaicin responses were repeated. Statistical analysis was by multiple analysis of variance.

\section{Results}

The effect of nedocromil on the capsaicin cough doseresponse relationship is shown in the figure. The dose of

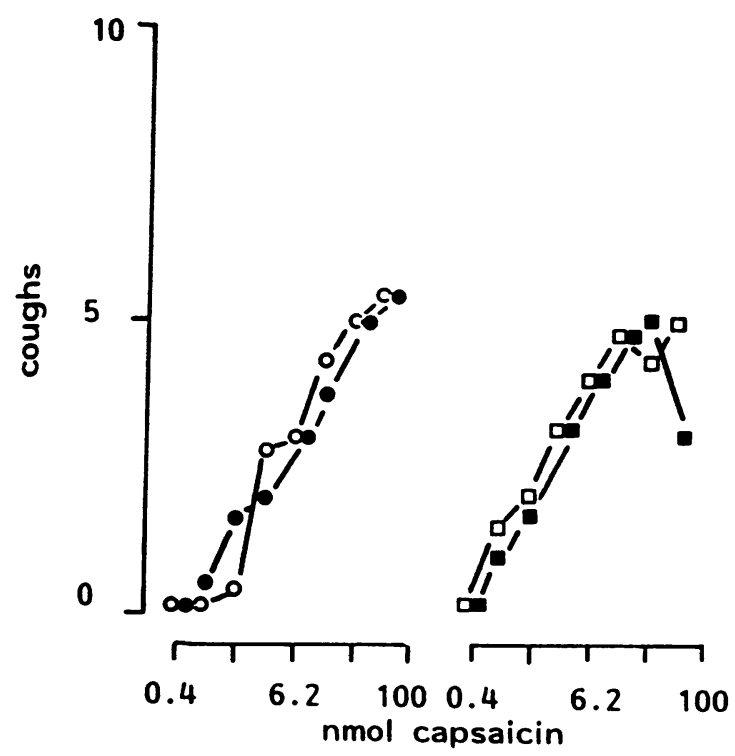

Median number of coughs at each dose of capsaicin before (open symbols) and after (closed symbols) nedocromil (squares) and placebo (circles). 
capsaicin causing two or more coughs $\left(D_{2}\right)$ was not altered by treatment with placebo or nedocromil sodium $(4 \mathrm{mg})$. The geometric mean $(95 \%$ confidence intervals) (nmol) was 3.2 $(3 \cdot 2-3 \cdot 2)$ before and 1.8 (1.2-2.8) after placebo and 1.6 (0.8$3.2)$ before and $1.6(1 \cdot 2-2 \cdot 1)$ after nedocromil. The dose causing five or more coughs $\left(D_{5}\right)$ was also unaffected by either treatment, being $17 \cdot 7(7 \cdot 0-44 \cdot 7)$ before and $28 \cdot 1(22 \cdot 3-35 \cdot 4)$ after placebo and $9.9(4.6-21.4)$ before and $9.9(4.6-21.4)$ after nedocromil.

The percentage increase in $R_{r s}$ after a single breath of capsaicin was also unaffected by either treatment, the mean (95\% confidence interval) percentage increase being $20(8.6-$ $31.4)$ before and $17 \cdot 7(7.9-27.5)$ after placebo and $18.0(12.3-$ $24.6)$ before and $22.5(4.9-40 \cdot 1)$ after nedocromil. The probability of a type 2 error $(\beta)$ causing a change of one dilution of capsaicin for either $D_{2}$ or $D_{5}$ to be missed after nedocromil was $<0.005$ (calculated from the between group variance of the data from the placebo day). The probability of a type 2 error $(\beta)$ causing a $29 \%$ difference in $R_{r s}$ to be missed was $<0.5$ (calculated from data on the placebo day).

\section{Discussion}

In this study a single dose of $4 \mathrm{mg}$ inhaled nedocromil sodium did not alter either cough or reflex bronchoconstriction caused by inhaling capsaicin. The results are therefore the same as those observed with sodium cromoglycate, ${ }^{45}$ which, like nedocromil sodium, inhibits the reflex bronchoconstriction caused by sulphur dioxide ${ }^{7}$ and bradykinin. ${ }^{8}$ Capsaicin cough and bronchoconstriction challenges can be repeated on the same day as there is no tachyphylaxis to this response. ${ }^{45}$ The probability therefore of a false negative result is low. The study implies that capsaicin stimulates sensory nerves different from those stimulated by inhaled sulphur dioxide and bradykinin in man. Although all three substances have been shown to stimulate $\mathrm{C}$ fibres ${ }^{9}$ in animals it is possible that capsaicin stimulates $\mathbf{C}$ fibres in the larynx and the other substances fibres elsewhere in the airways. Alternatively, the substances may stimulate fibres of different anatomical types in man.

We wish to acknowledge the support of the Medical Research Council, the Chest, Heart, and Stroke Association, and's Fisons PLC (which kindly supplied the nedocromil placebo). $\vec{\circ}$

\section{References}

1 Auty RM. The clinical development of a new agent for the treatment of airway inflammation, nedocromil sodium (Tilade). Eur J Respir Dis 1986;69:120-31.

2 Dixon CMS, Fuller RW, Barnes PJ. Effect of nedocromil sodium $\overrightarrow{-}$ on sulphur dioxide induced bronchoconstriction. Thorax $\mathrm{w}$
1987;42:462-5.

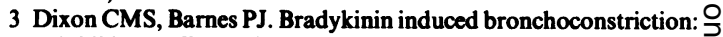
inhibitory effects of nedocromil sodium and cromolyn sodium $\rightarrow$ [abstract]. Am Rev Respir Dis 1988;137:A28.

4 Collier JG, Fuller RW. Capsaicin inhalation in man and the effects $O$ of sodium cromoglycate. Br J Pharmacol 1984;81:113-7.

5 Fuller RW, Dixon CMS, Barnes PJ. Bronchoconstrictor response to inhaled capsaicin in humans. J Appl Physiol 1985;58:1080-4. O

6 Landser DJ, Nagels J, Demedts M, Billiet L, Van de Woestijne KP. A new method to determine frequency characteristics of the $\overrightarrow{0}$ respiratory system. J Appl Physiol 1976;41:101-6.

7 Allistone A, Collier JG, Davidson RN, Fuller RW, Richardson PS. The effect of intravenous sodium cromoglycate on the bronchoconstriction induced by sulphur dioxide inhalation in man. Clin Sci 1985;68:227-32.

8 Fuller RW, Dixon CMS, Cuss FM, Barnes PJ. Bradykinin- $\overline{0}$ induced bronchoconstriction in humans. Am Rev Respir Dis 1987;135:176-80.

9 Coleridge HM, Coleridge JCG. Reflexes evoked from tracheobronchial tree and lung. Handbook of physiology. Section 3: The respiratory system. Vol 2. Bethesda, Maryland: American Physiological Society, 1986:395-429. 